\title{
Enhancing business intelligence for supply chain operations through effective classification of supplier management
}

\author{
Yee Ming Chen ${ }^{\mathrm{a}^{*}}$ and Yu-Pu Chiu ${ }^{\mathrm{b}}$
}

\begin{abstract}
annovation Center for Big Data and Digital Convergence and Department of Industrial Engineering and Management, Yuan Ze University, Taiwan, Republic of China (R.O.C)

${ }^{b}$ Department of Industrial Engineering and Management, Yuan Ze University, Taiwan, Republic of China (R.O.C)

C H R O N I C L E

Article history:

Received December 10,2013

Received in revised format

25 June 2014

Accepted July 172014

Available online

July 192014

Keywords:

Type-2 Fuzzy

Clustering

\section{A B S T R A C T}

Global supply chains have to manage production over the whole world. Therefore, production plants are needed to supply the demand of products and parts. Due to complication and uncertainty of production market, portfolio selection is one of the most challenging problems. Type-2(T2) fuzzy is a model, which provides the ability to handle the effect of uncertainty. Aiming at this problem, we propose a T2 supplier management system operation scheme, which not only employs fuzzy C-Means clustering algorithm by dynamically increasing cluster center, but also it achieves good classification performance. The key result is that fuzzy classification applications improve the planning and operating of supply and demand in a distributed production and global supply chain.
\end{abstract}

Classification

\section{Introduction}

Distributed production is the one of many issues in supply chain management area. There are many decisions that have to be involved to solve the problem, such as type of transportation mode, optimum path, type of product, and performance of supply chain elements. Supply chain management (SCM) is an integrative function, with primary responsibilities for linking major business functions and business processes within and across companies, into a cohesive and high-performing business model. It drives the coordination of processes and activities across areas of marketing, sales, product design, and information technology; Information systems are an important enabler of effective SCM, since with the advent of business intelligence, if there is no effective web-based information system in place, there is essentially no business. Any global company, though, can benefit from the successful implementation of SCM using different information systems options, including Enterprise Resource Planning (ERP) and Decision Support Systems (DSS) that are aimed towards assisting the different functional areas in a supply chain (Hayes \& Finnegan, 2005; Hashemzadeh et al., 2014). Every production plant needs Business intelligence (BI) functionalities to process classification and

* Corresponding author

E-mail address: chenyeeming@saturn.yzu.edu.tw (Y.M. Chen)

(C) 2014 Growing Science Ltd. All rights reserved.

doi: $10.5267 /$ j.uscm.2014.7.006 
delivering the parts, so that merchandise is produced and distributed at the right quantities, to the right locations, at the right time, in order to minimize system wide costs while satisfying service level requirement. The sources of uncertainty lie in the process of matching demand with supply. The following sources of uncertainty, which include delivery lead times, manufacturing yields, transportation times, machining times and operator performances, all lead to supply uncertainty that has significant impact on chain performance (Radjou, 2002). The increasing power of internet technologies has led to an increased demand for cost control, quality and innovation. Business organizations face a more complex and competitive environment than ever before in the Internet era. BI in supply chain allows companies to use the Internet for procuring direct or indirect materials, as well as handling value-added services (Fan et al., 2003). Developing a suitable BI approach for supplier selection is however a challenging research task. Often, there will be thousands of potential suppliers and identifying a subset of these suppliers can be a complex process of decision making. Among these BI approaches, soft computing techniques such as fuzzy logic, neural networks, and probabilistic reasoning draw most attention because of their abilities to handle uncertainty. In view of the fuzziness of goals, constraints and actions in real world, decision making is challenging for managers, engineers and researchers (Aliev et al., 2007). The concept of a fuzzy decision making was first proposed by Zadeh (1975). For example, at the beginning of a business, there may be some startup capital. However, during the period of business, it may happen that to meet an unexpected increased demand, the production is speeded up and for that, some extra capital is required. These augmented amounts are clearly uncertain and may be fuzzy in nature in the sense of degree of uncertainty. Various degrees of uncertainty are present in the different data sources used. This uncertainty is further amplified in the generated forecast by applying methods of analysis with varying degrees of inherent uncertainty. Furthermore, other data that is often used in supply chain resource planning such as transportation and other costs, customer satisfaction information, etc. is also uncertain. The expanded classic type-1 (T1) FL referred to as type-2 (T2) FL is an emerging methodology that is capable of dealing with more than static imprecision in decision making (Karnik $\&$ Mendel, 1999). Decision making is important in all the activity of supply chain involved due to the high level of risk associated with wrong decision. Therefore, FL and especially T2FL are particularly appropriate for this decision making problem. The aim of this study is evaluation suppliers in supply chain that are qualified for BI. The objective of this paper is to investigate the multiple attribute decision making problems to deal with the supplier selection in supply chain management with T2FL. The rest of the paper is organized as follows: next section briefly introduces some basic concepts related to type-2 fuzzy set and T2FL calculation in supplier management system. Section 3 illustratives example introduced the supplier management the test case used for evaluation. The final Section concludes the paper with summary and future research directions.

\section{Type-2 Fuzzy Logic for Supplier Management System}

\subsection{Type-2 Fuzzy Set}

A type-1(T1) fuzzy set, A which is in terms of a single variable, $x \in X$, is characterized by a membership function that takes values in the interval $[0,1]$, and can be defined as follow,

$A=\left\{\left(x, u_{A}(x) \mid \forall x \in X\right\}\right.$

where $u_{A}(x)$ is membership function. Type 2 (T2) fuzzy sets was introduced first by Zadeh (1975) as an extension of the concept of an ordinary fuzzy set. T2 fuzzy sets are high level representation of vague data, and can handle the uncertainties in T1 fuzzy sets, such as, the meaning of the word and noise measurements.

A T2 fuzzy set, denoted $\widetilde{\mathrm{A}}$, is characterized by a T2 membership function, $\mathrm{u}_{\widetilde{\mathrm{A}}}(\mathrm{x}, \mathrm{u})$, where $X$ is the universal set, $\mathrm{x} \in \mathrm{X}$ and $\mathrm{u} \in \mathrm{J}_{\mathrm{X}} \subseteq[0,1]$. That is 
$\widetilde{\mathrm{A}}=\left\{\left((\mathrm{x}, \mathrm{u}), \mathrm{u}_{\widetilde{\mathrm{A}}}(\mathrm{x}, \mathrm{u})\right) \mid \forall \mathrm{x} \in \mathrm{X}, \forall \mathrm{u} \in \mathrm{J}_{\mathrm{x}} \sqsubseteq[0,1]\right\}$

where $0 \leq \mathrm{u}_{\widetilde{\mathrm{A}}}(\mathrm{x}, \mathrm{u}) \leq 1$. Accordingly, at each value of $x$, say $x=x^{\prime}$

$\mathrm{u}_{\widetilde{\mathrm{A}}}\left(\mathrm{x}^{\prime}\right)=\sum_{\mathrm{u} \in \mathrm{J}_{\mathrm{x}^{\prime}}} \mathrm{f}_{\mathrm{x}^{\prime}}(\mathrm{u}) / \mathrm{u}$ for $\mathrm{u} \in \mathrm{J}_{\mathrm{x}^{\prime}} \subseteq[0,1]$ and $\mathrm{x}^{\prime} \in \mathrm{X}$

where $\mathrm{u}_{\widetilde{\mathrm{A}}}(\mathrm{x})$ represents the secondary membership function.

Uncertainty about the shape and position of $\widetilde{\mathrm{A}}$ is conveyed by the union of all the primary memberships, which is called the footprint of uncertainty (FOU).

$\operatorname{FOU}(\widetilde{\mathrm{A}})=\bigcup_{\forall \mathrm{x} \in \mathrm{X}} \mathrm{J}_{\mathrm{x}}=\left\{(\mathrm{x}, \mathrm{u}): \mathrm{u} \in \mathrm{J}_{\mathrm{X}} \subseteq[0,1]\right\}$

Fig. 1 shows a T2 fuzzy set with an uncertain mean. The FOU can be described in terms of upper membership function (UMF) and lower membership function (LMF), denoted as $\overline{\mathrm{u}}_{\widetilde{A}}(\mathrm{x})$ and $\underline{\mathrm{u}}_{\tilde{A}}(\mathrm{x})$, which are two T1 membership functions that are bounds for the FOU of a T2 fuzzy set. So a T2 fuzzy set can also be given as follows:

$\widetilde{\mathrm{A}}=\left\{\left(\mathrm{x}, \overline{\mathrm{u}}_{\widetilde{\mathrm{A}}}(\mathrm{x}), \underline{\mathrm{u}}_{\widetilde{\mathrm{A}}}(\mathrm{x})\right) \mid \forall \mathrm{x} \in \mathrm{X}, \underline{\mathrm{u}}_{\widetilde{\mathrm{A}}}(\mathrm{x}) \leq \mathrm{u}(\mathrm{x}) \leq \overline{\mathrm{u}}_{\widetilde{\mathrm{A}}}(\mathrm{x}), \mathrm{u} \in[0,1]\right\}$

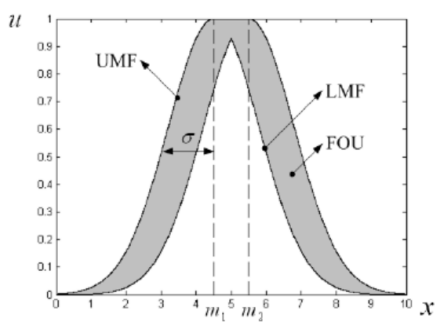

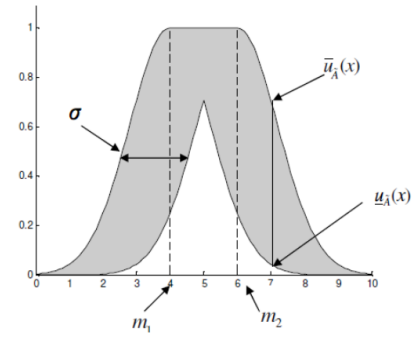

Fig. 1. Type 2 fuzzy set with uncertain mean

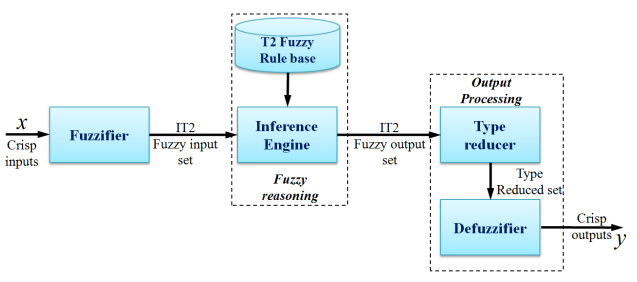

Fig. 2. Type-2 Fuzzy Logic System (T2FLS)

The T2 Gaussian MF is constructed by a Gaussian primary MF and a T2 secondary MF. Fig. 1 shows a two-dimensional T2 Gaussian MF with an adjustable uncertain mean in $\left[\mathrm{m}_{1}, \mathrm{~m}_{2}\right]$ and standard deviation $\sigma$. It is described as follows,

$\mathrm{u}_{\widetilde{\mathrm{A}}}(\mathrm{x})=\exp \left[-\frac{1}{2}\left(\frac{\mathrm{x}-\mathrm{m}}{\sigma}\right)^{2}\right], \mathrm{m} \in\left[\mathrm{m}_{1}, \mathrm{~m}_{2}\right]$

A type 2 Fuzzy Logic System (T2FLS) has five subsystems; fuzzifier, inference system, rule base, type-reducer and defuzzifier (see Fig. 2). The structure of rules in the T2FLS and its inference engine is similar to those in T1FLS. The T2FLS works as follows: the crisp inputs are first fuzzified into T2FSs, which then activate the inference engine and the rule base to produce output T2FSs. These T2FSs are then processed by a type-reducer (which combines the output sets and then performs a centroid calculation), leading to an interval T1FSs called the type-reduced set. A defuzzifier then defuzzifies the type-reduced set to produce crisp outputs.

\subsection{The Supplier Management System using T2 Fuzzy Logic Calculation}

The suppler management system is placed on T2 fuzzy methodology due to its classification to account for uncertainties for decision making. T2 fuzzy sets have been chosen to represent antecedents of fuzzy rules. A template of a fuzzy rule in the Mamdani framework is the following 
$R^{n}$ : if $x_{1}$ is $\widetilde{A}_{1}^{n}$ and $\cdots$ and $x_{i}$ is $\widetilde{A}_{i}^{n}$ then $y$ is $Y_{j}^{n}$,

where $R^{n}$ is the $n$th rule, $n=1, \cdots N$, with each rule having $i$ antecedents, $\widetilde{A}_{i}^{n}(i=1,2, \ldots, I)$ is the T2 fuzzy membership functions of input variable. $Y_{j}^{n}=\left[y_{j}^{n}, \bar{y}_{j}^{n}\right]$ is an interval output vector of the $j$ th, which is the average of the consequent T2 fuzzy set representing the class that input features are assigned.

Assume the input vector is $\mathrm{x}=\left(\mathrm{x}_{1}, \mathrm{x}_{2}, \cdots, \mathrm{x}_{\mathrm{I}}\right)$. The design of supplier management system using $\mathrm{T} 2$ fuzzy logic involve the following steps

Compute the membership of $x_{i}$ on each $\widetilde{A}_{i}^{n} \cdot\left[u_{A_{i}^{n}}\left(x_{i}\right), u_{\bar{A}_{i}^{n}}\left(x_{i}\right)\right], i=1, \cdots I n=1, \cdots N$

Compute the firing interval of the nth rule, $\mathrm{F}^{\mathrm{n}}(\mathrm{x})$ :

$\mathrm{F}^{\mathrm{n}}(\mathrm{x})=\left[\mathrm{u}_{\underline{A}_{\mathrm{i}}^{\mathrm{n}}}\left(\mathrm{x}_{\mathrm{i}}\right) \times \cdots \times \mathrm{u}_{\underline{A}_{I}^{\mathrm{n}}}\left(\mathrm{x}_{\mathrm{I}}\right), \mathrm{u}_{\overline{\mathrm{A}}_{\mathrm{i}}^{\mathrm{n}}}\left(\mathrm{x}_{\mathrm{i}}\right) \times \cdots \times \mathrm{u}_{\overline{\mathrm{A}}_{\mathrm{I}}^{\mathrm{n}}}\left(\mathrm{x}_{\mathrm{I}}\right)\right] \equiv\left[\underline{\mathrm{f}}^{\mathrm{n}}, \mathrm{f}^{-\mathrm{n}}\right]$.

Perform type-reduction to combine $\mathrm{F}^{\mathrm{n}}(\mathrm{x})$ and the corresponding rule consequents. There are many such methods. The most commonly used one is the center-of-sets (COS) type-reducer

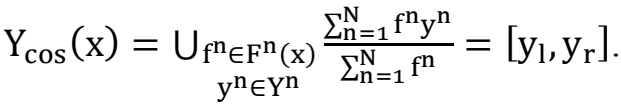

It has been shown that

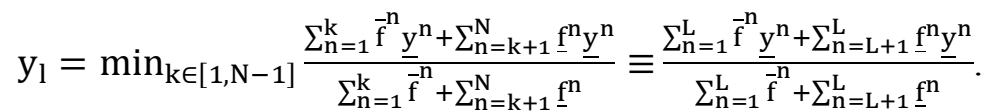

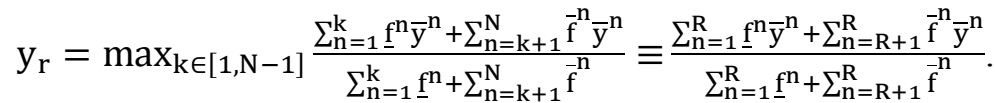

where the switch points $\mathrm{L}$ and $\mathrm{R}$ are determined by

$\underline{\mathrm{y}}^{\mathrm{L}} \leq \mathrm{y}_{1} \leq \underline{\mathrm{y}}^{\mathrm{L}+1}$.

$\overline{\mathrm{y}}^{\mathrm{R}} \leq \mathrm{y}_{\mathrm{r}} \leq \overline{\mathrm{y}}^{\mathrm{R}+1}$.

and $\left\{\underline{y}^{\mathrm{n}}\right\}$ and $\left\{\overline{\mathrm{y}}^{\mathrm{n}}\right\}$ have been sorted in ascending order, respectively.

$\mathrm{y}_{1}$ and $\mathrm{y}_{\mathrm{r}}$ can be computed efficiently using the Karnik-Mendel (KM) algorithms [Karnik and Mendel, 2001; $\mathrm{Wu}$ and Mendel, 2009 ]. To compute $\mathrm{y}_{1}$ and $\mathrm{y}_{\mathrm{r}}$, the steps are

(1) Sort $\mathrm{y}_{\mathrm{n}}(\mathrm{n}=1,2, \cdots, N)$ in increasing order and call the sorted $\mathrm{y}^{\mathrm{n}}$ by the same name, but now $\underline{y}^{1} \leq \underline{y}^{2} \leq \cdots \leq \underline{y}^{N}$. Match the weights $F^{n}(x)$ with their respective $\underline{y}^{n}$ and renumber them so that their index corresponds to the renumbered $\mathrm{y}^{\mathrm{n}}$.

(2) Compute $\mathrm{y}_{1}$ as $\mathrm{y}=\frac{\sum_{n=1}^{N} \underline{\underline{y}}^{\mathrm{n}} \mathrm{f}^{\mathrm{n}}}{\sum_{n=1}^{N} \mathrm{f}^{\mathrm{n}}}$ by initially setting $\mathrm{f}^{\mathrm{n}}=\frac{\mathrm{f}^{\mathrm{n}}+-_{\mathrm{f}}^{\mathrm{n}}}{2}$ for $\mathrm{n}=1,2, \cdots, \mathrm{N}$

(3) Find $\mathrm{L}(1 \leq \mathrm{L} \leq \mathrm{N}-1)$ such that $\underline{\mathrm{y}}^{\mathrm{L}} \leq \mathrm{y} \leq \underline{\mathrm{y}}^{\mathrm{L}+1}$

(4) Set $\mathrm{f}^{\mathrm{n}}=\left\{\begin{array}{ll}\overline{\mathrm{f}}^{\mathrm{n}} & \mathrm{n} \leq \mathrm{k} \\ \mathrm{f}^{\mathrm{n}} & \mathrm{n}>\mathrm{k}\end{array}\right.$ and compute $\mathrm{y}^{\prime}=\frac{\sum_{n=1}^{N} \underline{\underline{y}}^{\mathrm{n}} \mathrm{f}^{\mathrm{n}}}{\sum_{\mathrm{n}=1}^{N} \mathrm{f}^{\mathrm{n}}}$

(5) Check if $\mathrm{y}^{\prime}=\mathrm{y}$. If yes, stop and $\mathrm{y}_{\mathrm{l}}=\mathrm{y}$ and $\mathrm{L}=\mathrm{k}$. If no, go to Step (6).

(6) Set y = y' and go to Step (3). 
The procedure for computing $y_{r}$ is very similar to the one for $y_{l}$. Just replace $y_{r}$ by $y_{1}$ and, in Step (3) find $\mathrm{R}(1 \leq \mathrm{R} \leq \mathrm{N}-1)$ such that $\underline{\mathrm{y}}^{\mathrm{R}} \leq \mathrm{y} \leq \underline{\mathrm{y}}^{\mathrm{R}+1}$.

Compute the defuzzified output as

$\mathrm{y}=\frac{\mathrm{y}_{1}+\mathrm{y}_{\mathrm{r}}}{2}$.

The calculation of designed supplier management system with T2 fuzzy logic has been shown in Fig. 3 , briefly.

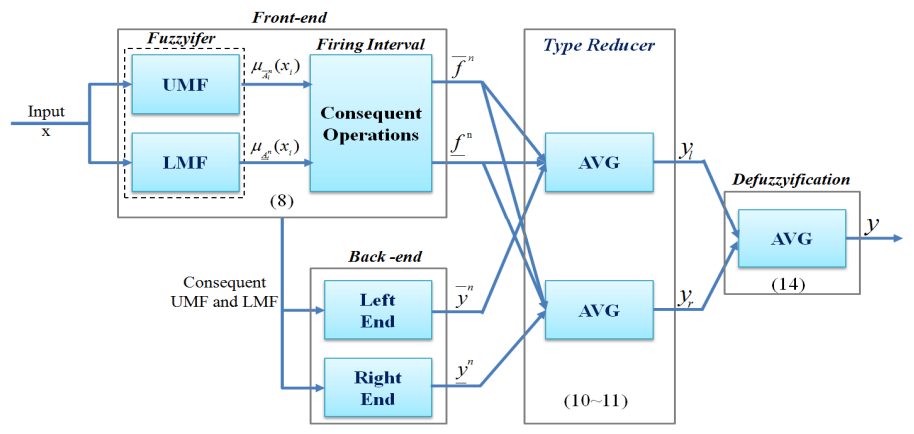

Fig. 3. Calculation of design of supplier management system using T2 fuzzy logic

\subsection{T2 supplier management system operation scheme}

Our proposed T2 supplier management system based UMF and LMF bounds can be capable of account for noisy measurements or operate under random disturbances associated with multiple supplier recordings. Additionally, the calculation procedure is quite simple and can be used for all features simultaneously as in the case of high dimensional input data.

The operation scheme of a T2 supplier management system is realized in two stages. At first, the structure is identified and then, secondly, determines FOU of each T2 supplier management system MFs. An initial T2 supplier management system is created to reflect the distribution of the supplier features and their corresponding feature type assignment in the input-output space. For this purpose an unsupervised learning clustering using Fuzzy C-means algorithm, which allows for establishing a parsimonious architecture of the fuzzy system. Then obtain the generated T2 supplier management system MF, the FOU needs to be further determined. The UMF and LMF are obtained by the following heuristic method from the same sample data set.

In this section, we ,firstly, give a brief illustration of the fuzzy c-means (FCM) algorithm and then discuss the UMF and LMF parameter determination in T2 supplier management system MF. The FCM algorithm is a method of clustering which allows one piece of data to belong to two or more clusters. The FCM is an iterative algorithm using the necessary conditions for a minimize of the objective function $\mathrm{J}_{\mathrm{FCM}}$ (Rhee, 2007) with

$\mathrm{J}_{\mathrm{FCM}}(\mathrm{u}, \mathrm{c})=\sum_{\mathrm{i}=1}^{\mathrm{C}} \sum_{\mathrm{j}=1}^{\mathrm{n}} \mathrm{u}_{\mathrm{ij}}^{\mathrm{m}}\left\|\mathrm{x}_{\mathrm{j}}-\mathrm{c}_{\mathrm{i}}\right\|^{2}$

where $m$ is any real number greater than $1, u_{i j}$ is the degree of membership of $x_{j}$ in the cluster $i, x_{j}$ is the $\mathrm{jth}$ of d-dimensional measured data, $\mathrm{c}_{\mathrm{i}}$ is the d-dimension center of the cluster, and $\left\|^{*}\right\|$ is any norm expressing the similarity between any measured data and the center. Several studies have shown that reasonable clustering results can be obtained using $m=2$ (Hwang \& Rhee, 2007; Rhee, 2007). The necessary conditions for a minimize $(\mathrm{u}, \mathrm{c})$ of $\mathrm{J}_{\mathrm{FCM}}$ are the following update equations:

$\mathrm{u}_{\mathrm{ij}}=\frac{\left\|\mathrm{x}_{\mathrm{j}}-\mathrm{c}_{\mathrm{i}}\right\|^{-2 /(\mathrm{m}-1)}}{\sum_{\mathrm{k}=1}^{\mathrm{C}}\left\|\mathrm{x}_{\mathrm{j}}-\mathrm{c}_{\mathrm{k}}\right\|^{-2 /(m-1)}}$ 
$c_{i}=\frac{\sum_{j=1}^{n} u_{i j}^{m} x_{j}}{\sum_{j=1}^{n} u_{i j}^{m}}$

Using the center update Eq. (16) and Eq. (17) gives us the T2 MF which FCM algorithm is given in Table 1.

\section{Table 1}

Fuzzy c-means algorithm

initialize $C=$ number of clusters

initialize $c_{i}$ (cluster centers)

Repeat

For $j=1$ to $n:$ Update $u_{i}\left(x_{j}\right)$ applying (16)

For $i=1$ to $C$ :Update $c_{i}$ with (17) with current $u_{i}\left(x_{j}\right)$

Until $c_{i}$ estimate stabilize

After the initial structure of the T2 Fuzzy Classifier has been set up, its FOU by taking intersections of all upper and lower memberships for all features by our heuristic method. If we choose the min operation as intersection, the FOU can be expressed as (Choi \& Rhee, 2009)

$\mathrm{U}_{\forall \mathrm{x} \in \mathrm{X}}[\underline{\mathrm{u}}(\mathrm{x}), \overline{\mathrm{u}}(\mathrm{x})]=\mathrm{U}_{\forall \mathrm{x} \in \mathrm{X}}\left\{\min _{\mathrm{i}}\left[\underline{\mathrm{u}}_{\mathrm{i}}\left(\mathrm{x}_{\mathrm{i}}\right)\right], \min _{\mathrm{i}}\left[\overline{\mathrm{u}}_{\mathrm{i}}\left(\mathrm{x}_{\mathrm{i}}\right)\right]\right\}$

where, $\overline{\mathrm{u}}(\mathrm{x})$ and $\underline{\mathrm{u}}(\mathrm{x})$ are the minimum UMF and LMF among all UMFs and LMFs for all features, respectively.

The overall operation scheme of supplier management system is summarized as follows.

(1) T2 supplier management system structure identification using Eq. (16) and Eq. (17) in Fuzzy Cmeans algorithm;

(2) Design the FOU for each T2 supplier management system MFs using Eq. (5) and Eq. (18);

(3) Calculation the defuzzified output of T2 supplier management system, Eqs. (7-14), for suppliers classification.

\section{Illustrative Example}

Consider the case where there are two products $\left(\mathrm{X}_{1}\right.$ and $\left.\mathrm{X}_{2}\right)$ that are supplied by three supplier types $\mathrm{S}_{\mathrm{A}}, \mathrm{S}_{\mathrm{B}}$, and $\mathrm{S}_{\mathrm{C}}$. Two different parts $\mathrm{P}_{11}, \mathrm{P}_{12}$ and $\mathrm{P}_{21}, \mathrm{P}_{22}$ are assembled to form products $\mathrm{X}_{1}$ and $\mathrm{X}_{2}$ respectively. For $\mathrm{X}_{1}$, supplier $\mathrm{S}_{\mathrm{A}}$ can only supply only one of the parts $\left(\mathrm{P}_{11}\right)$, and the other part $\left(\mathrm{P}_{12}\right)$ has to be ordered from supplier $\mathrm{S}_{\mathrm{C}}$. Supplier $\mathrm{S}_{\mathrm{C}}$, on the other hand, can supply both the parts $\left(\mathrm{P}_{11}\right.$ and $\left.\mathrm{P}_{12}\right)$. Similarly, For $\mathrm{X}_{2}$, supplier $\mathrm{S}_{\mathrm{B}}$ can only supply only one of the parts $\left(\mathrm{P}_{21}\right)$, and the other part $\left(\mathrm{P}_{22}\right)$ has to be ordered from supplier $\mathrm{S}_{\mathrm{C}}$. Supplier $\mathrm{S}_{\mathrm{C}}$, on the other hand, can supply both the parts $\left(\mathrm{P}_{21}\right.$ and $\mathrm{P}_{22}$ ).

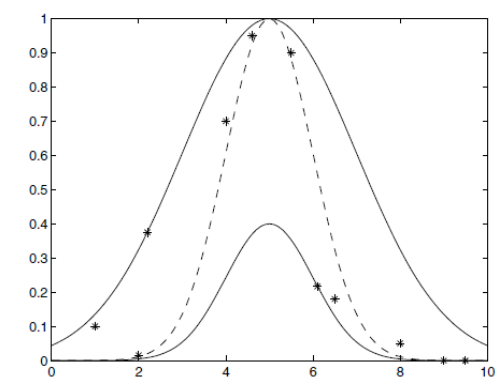

Fig. 4. Two products sample dataset for $\mathrm{S}_{\mathrm{A}}, \mathrm{S}_{\mathrm{B}}$, and $\mathrm{S}_{\mathrm{C}}$ 
Supplier management system will generate the most appropriate e-procurement rules of the supplier for any given combination attribute of lead-time, quantity and price. The training examples present the idea of the interval uncertainty fitting as the Fig. 4. The training examples by randomly normalization sampling for attributes values and assigning the most appropriate supplier to each of these examples.

The T2 supplier management system generated by the operation scheme from patterns in Fig. 4 by setting the number of prototypes for each class be one and $\mathrm{m} 1=0.3, \mathrm{~m} 2=0.5$ in Eq. (6). The upper and lower membership functions are plotted to describe the T2 supplier management system in these Figs. 5-7.

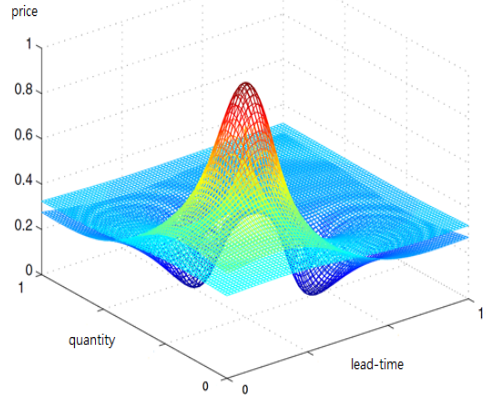

Fig. 5. The T2 supplier management system corresponding with class "S $\mathrm{A}_{\mathrm{A}}$ "

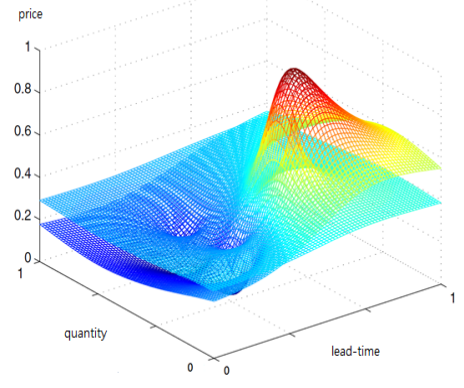

Fig. 6. The T2 supplier management system corresponding with class " $\mathrm{S}_{\mathrm{B}}$ "

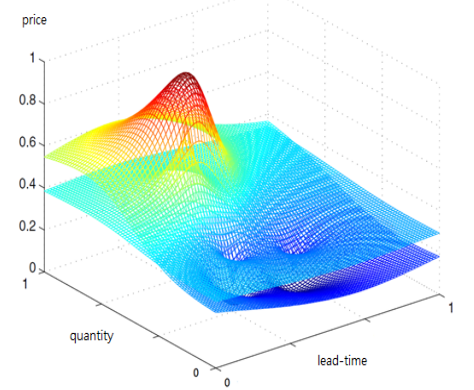

Fig. 7. The T2 supplier management system corresponding with class "S $\mathrm{S}_{\mathrm{C}}$ "

For our operation scheme, the T2 supplier management system classification result of one run for the sample dataset is shown in Fig. 8, where the patterns belonging to three classes are denoted by $\mathrm{S}_{\mathrm{A}}, \mathrm{S}_{\mathrm{B}}$, and $\mathrm{S}_{\mathrm{C}}$, the black points and red points represent training patterns and testing patterns respectively and the points covered by blue squares are misclassified patterns.

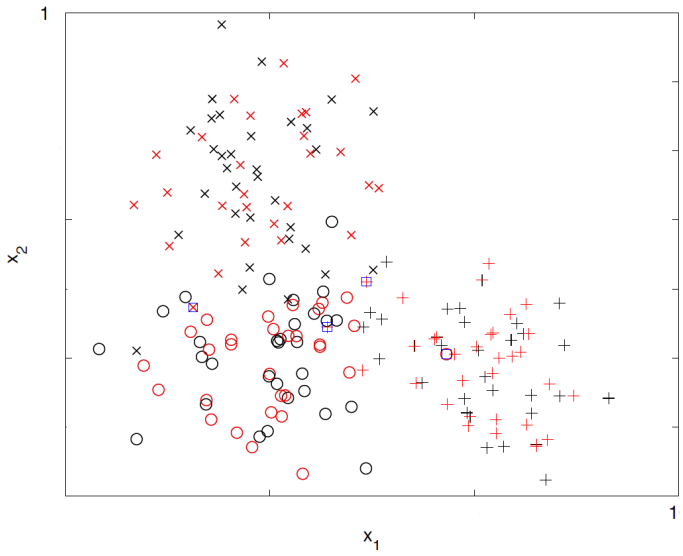

Fig. 8. The classification result of the proposed $T 2$ supplier management system in one run

\section{Conclusions}

This research has presented a Type-2 fuzzy logic of supplier management system operation scheme, framework design for BI, which could aid business executives in deciding the appropriate supplier management to use. The first step of this supplier management system operation scheme has applied fuzzy c-means partition and expands upper and lower membership functions. The second step relied on the application of T2 fuzzy logic of the classification functions. Therefore, boundary membership functions of T2 fuzzy sets better fit to data. Using T2FL allows us to model the fuzziness present in supply chain operation, allowing the user to input data that is uncertain. Work is ongoing. Future 
work will include testing the model on more complex problems that have been solved by other methods to allow comparison, and applying the model to global supply chain scenarios.

\section{Acknowledgments}

This research work was sponsored by the National Science Council, R.O.C., under project number NSC 102-2622-E-155 -010 -CC3.

\section{References}

Aliev, R. A., Fazlollahi, B., Guirimov, B. G., \& Aliev, R. R. (2007). Fuzzy-genetic approach to aggregate production-distribution planning in supply chain management. Information Sciences, 177(20), 4241-4255.

Choi, B. I., \& Chung-Hoon Rhee, F. (2009). Interval type-2 fuzzy membership function generation methods for pattern recognition. Information Sciences, 179(13), 2102-2122.

Fan, M., Stallaert, J., \& Whinston, A. B. (2003). Decentralized mechanism design for supply chain organizations using an auction market. Information Systems Research, 14(1), 1-22.

Hashemzadeh, G., Modiri, M., \& Rahimi, Z. (2014). Identification and ranking effective factors on establishment of green supply chain management in railway industry. Uncertain Supply Chain Management. 2(4).

Hayes, J., \& Finnegan, P. (2005). Assessing the of potential of e-business models: towards a framework for assisting decision-makers. European Journal of Operational Research, 160(2), 365-379.

Hwang, C., \& Rhee, F. H. (2007). Uncertain fuzzy clustering: interval type-2 fuzzy approach to Cmeans. Fuzzy Systems, IEEE Transactions on, 15(1), 107-120.

Karnik, N. N., \& Mendel, J. M. (1999). Applications of type-2 fuzzy logic systems to forecasting of time-series. Information Sciences, 120(1), 89-111.

Karnik, N. N., \& Mendel, J. M. (2001). Centroid of a type-2 fuzzy set.Information Sciences, 132(1), 195-220.

Radjou, N. (2002). Building an adaptive supply network. Supply-Chain World North America, April 22-24, New Orleans, LA.

Chung-Hoon Rhee, F. (2007). Uncertain fuzzy clustering: insights and recommendations. Computational Intelligence Magazine, IEEE, 2(1), 44-56.

Wu, D., \& Mendel, J. M. (2009). Enhanced karnik--mendel algorithms. Fuzzy Systems, IEEE Transactions on, 17(4), 923-934.

Zadeh, L. A. (1975). The concept of a linguistic variable and its application to approximate reasoning-I. Information sciences, 8(3), 199-249. 